\title{
Adolescentes Migrantes, CARTOGRafías, PASEOS POR BILBAO Y MAPAS SOÑADOS
}

\author{
Migrant Teenagers, Walks around Bilbao and Mapping Dreams
}

\author{
Karmele Mendoza Pérez \\ karmelemp@unex.es \\ Universidad de Extremadura
}

\section{Marta Morgade Salgado}

mmorgade.s@gmail.com

Universidad Autónoma de Madrid

RESUMEN: El objetivo principal de este artículo es describir las prácticas de vida y socialidad de adolescentes migrantes en la ciudad de Bilbao (País Vasco, España) a partir de sus vivencias y perspectivas. Para ello utilizamos metodología etnográfica general y, en particular, un taller construido a partir de distintas técnicas artísticas, que invitó a cinco menores migrantes, residentes en un centro de menores de la provincia de Bizkaia (País Vasco), a realizar una cartografía por Bilbao para la generación del material de análisis sobre sus rutinas y actividades expresivas en la ciudad. Esta estrategia metodológica y el mapa, como producto final de la cartografía, permiten entender y aportar un enfoque holístico del fenómeno migratorio de estos adolescentes y jóvenes en la ciudad. Estos adolescentes y jóvenes migrantes, más allá de ocupar físicamente una serie de espacios, se revindican como ciudadanos plenos y en constante interacción y negociación entre amigos, paisanos, familia, la escuela, la comunidad en el país de origen.

Palabras Clave: adolescentes migrantes, menores extranjeros no acompañados, cartografías, ciudad, tecnologías digitales, transnacionalismo, prácticas expresivas.

Aвstract: The main objective of this article is to study the life and social practices of migrant adolescents in the city of Bilbao (Basque Country, Spain) 
through their experiences and perspectives. To this end, we used ethnographic methodology, specifically a workshop structured around several artistic techniques, in which five migrant minors living in a Centre for Minors in the Basque province of Bizkaia were invited to create their own maps of Bilbao. The authors then used this material to analyse their routines and the activities that expressed their realities in the city. The holistic approach of this methodological strategy and the maps produced allowed us to understand the migratory experiences of these adolescents and young people. As well as physically occupying a series of spaces, these young migrant lay claim to their status as full citizens, in constant interaction and negotiation with friends, family, school and the community in their country of origin.

KEYWORDs: migrant adolescents, unaccompanied foreign minors, cartography, city, digital technologies, transnationalism, expressive practices.

ResUM: L'objectiu principal d'aquest article és descriure les pràctiques de vida i socialitat d'adolescents migrants a la ciutat de Bilbao (País Basc, Espanya) a partir de les seues vivències i perspectives. Per a això utilitzem metodologia etnogràfica general i, en particular, un taller construït a partir de diferents tècniques artístiques, que va convidar a cinc menors migrants, residents en un centre de menors de la província de Biscaia (País Basc), a realitzar una cartografia per Bilbao per a la generació del material d'anàlisi sobre les seues rutines i activitats expressives a la ciutat. Aquesta estratègia metodològica $i$ el mapa, com a producte final de la cartografia, permeten entendre $i$ aportar un enfocament holístic del fenomen migratori d'aquests adolescents i joves a la ciutat. Aquests adolescents i joves migrants, més enllà d'ocupar físicament un seguit d'espais, es reivindiquen com a ciutadans plens i en constant interacció i negociació entre amics, paisans, família, l'escola, la comunitat al país d'origen.

Paraules clau: adolescents migrants, menors estrangers no acompanyats, cartografies, ciutat, tecnologies digitals, transnacionalisme, pràctiques expressives. 


\section{Introducción}

$\mathrm{E}$ 1 comienzo del nuevo milenio representa un importante punto de inflexión en la comprensión de la realidad social del Estado Español y especialmente en el análisis de la complejidad de las ciudades (García Almirall). Así, en el 2000 en las principales ciudades de la Comunidad Autónoma del País Vasco (CAPV) comenzaron a ser visibles los denominados «Menores Extranjeros No Acompañados». ${ }^{1}$

Poco después, en el 2007, Bizkaia (País Vasco) alcanzaba una de sus cotas más altas respecto a nuevos menores migrantes acogidos por los servicios sociales (Ararteko, 2014, p. 43). Con unos servicios sociales desbordados era fácil encontrar a jóvenes inhalando en la calle y buscándose la vida por los barrios altos de Bilbao. Las calles y sus adyacentes poseen la característica fundamental de acceso amplio no restringido, una accesibilidad abierta a la inmensa mayoría de seres (Delgado, 2007). No obstante, en las calles, en estos lugares de encuentros leves y efímeros, los jóvenes migrantes no gustaban, «no confiaban en ellos», eran continuas las quejas sobre «los problemas que daban», «siempre la liaban cuando consumían inhalantes». Por supuesto, también había jóvenes que veían a esos menores migrantes como «niños como nosotros» (Mendoza Pérez, 2017a).

En estos encuentros efímeros, los unos con los otros, lo habitual era que finalmente los «autóctonos» iguales en edad pusieran distancia respecto de los «iguales migrantes», impusieran sus cosmovisiones o «patrones» mediante una apropiación del terreno urbano (Delgado, 2007). Apropiaciones que rompen con la movilidad para la que está diseñada la ciudad y la movilidad que caracteriza las realidades de estos jóvenes. A pesar de ese acoso contra la movilidad y visibilización de los menores migrantes en las calles, estos jóvenes muestran prácticas propias que buscan tanto formar parte de la ciudad como crear nuevas formas de hacer y ser ciudad. Esto se nos plantea como una realidad inquietante de nuestras ciudades, atractiva de explorar.

Por otro lado, no podemos olvidar que el desarrollo tecnológico y la transformación del ser adolescente migrante en la ciudad son hechos relacionados

1. En este artículo denominaremos a los Menores Extranjeros No Acompañados como adolescentes migrantes o, migrantes adolescentes indistintamente. 
(Mendoza Pérez y Morgade Salgado, 2018). Aunque a los jóvenes migrantes se les limita la oportunidad de transitar libremente las calles, en las líneas que siguen veremos que la distancia física, incluso las fronteras, no representan necesariamente siempre un obstáculo para generar intercambios, y prácticas, de una manera creativa dentro de ciertos espacios en las ciudades, aparentemente hostiles (Mocusí Ferré, 2018). Es más, hoy en día es difícil estar aislado del resto del pueblo, ciudad, e incluso del mundo, nuestro globalizado mundo; las ciudades se constituyen como espacios donde ser/estar móviles. Las TIC posibilitan, y median, en los procesos de aprendizaje y socialización de estos adolescentes migrantes, ya que favorecen la movilidad y la interacción, aunque no haya desplazamiento geográfico. Por tanto, los espacios virtuales no desalojan a los espacios materiales, ni viceversa; ambos marchan de forma interconectada (Morgade Salgado, Poveda y González Patiño, 2014).

Así pues, el objetivo de esta investigación es dar cabida a los conocimientos situados de los menores migrantes que transitan la ciudad de Bilbao y sus alrededores. Así, a lo largo de los siguientes apartados invitaremos al lector a cambiar la perspectiva del alejamiento, mientras se desplaza por una sucesión de ambientes y territorios en los que adolescentes migrantes despliegan y performan su ciudadanía. El recorrido comienza con unas imágenes de las políticas de cuidado e institucionalización de sus vidas, que a modo de fronteras reales, y simbólicas, pretenden separarlos del día a día de la ciudad, controlarlos o invisibilizarlos. Para a continuación, a partir de una propuesta metodológica, a modo de instrumento para derribar fronteras, muestra las prácticas y experiencias de verdaderos participantes de nuestras ciudades. En este recorrido veremos que la movilidad se despliega en el espacio y tiempo de la ciudad mediado por medios digitales que conectan nuestras ciudades con las ciudades de origen de los jóvenes. Las vidas en movimiento de los migrantes dibujan ciudades fluidas en nuestro tiempo (Bauman, 2005).

\section{La red residencial y cotidianidad en un centro de menores mi- grantes en Bizkaia}

La atención y los recursos residenciales para los menores migrantes en Bizkaia ha ido fluctuando en función del número de menores que llegaba. 
Mendoza Pérez y Belarra (2015) señalan que a partir del 2013 y con el descenso en la llegada de nuevos menores a tierras vascas, muchos de los recursos destinados a estos jóvenes se fueron cerrando o reconvirtiéndose en recursos destinados a menores autóctonos (p. 245). Sin embargo, tras varios años de tendencia descendente, a partir del 2016 ha aumentado la llegada de menores migrantes, haciendo que se vuelvan a reabrir muchos de los centros que fueron cerrados (Ararteko, 2016).

De forma breve, resumiremos cuál es el itinerario de los menores migrantes una vez que son detectados en Bizkaia. En primer lugar, serán derivados a un centro de primera acogida, que es sólo para la atención inmediata de los menores, aunque por sobreocupación de la red de protección suelen permanecer en éste más tiempo del esperado. Después, se los derivará a recursos residenciales estables. Cabe señalar que al igual que en otras comunidades autónomas, como Cataluña, Madrid y Andalucía, en el País Vasco existen dos redes segregadas de protección. Es decir, una red de protección y recursos residenciales para los menores migrantes y otra para los menores autóctonos (Mendoza Pérez y Belarra, 2015).

Los centros de primera acogida y residenciales para menores migrantes suelen ser de gran tamaño (Empez, 2015, p. 237), y en muchas ocasiones están alejados del núcleo urbano, incluso rodeados por rejas (Aierbe, Taulats, Manzani y Luciani, 2010). A su llegada a los centros de primera acogida se les proporciona ropa para cubrir sus necesidades básicas de vestido. Ésta suele estar comprada al por mayor por lo que las prendas se parecen mucho unas a otras, lo que hace a los chicos fácilmente identificables como «niños de centro de menores» (Arrazola, 2014, p. 137).

El centro residencial en el que se sitúa este trabajo, y que llamaremos Urrun, es uno de esos centros residenciales que se encuentra alejado del núcleo urbano de Bilbao y localizado en una zona rural colindante. Aunque Urrun no es un centro de reforma, los menores tienen prohibido salir por el pueblo. Deben ir del centro al colegio y del colegio al centro y, en caso de quedarse o salir al pueblo sin un educador, serán sancionados. Esto, como señala Empez (2015, p. 212), dificulta que los menores puedan pertenecer a un barrio, obstaculiza la creación de redes sociales con pares autóctonos. Pero, además, fomenta la otredad y justifica el falso estereotipo de «crimi- 
nales» tanto en la sociedad de acogida como en su autopercepción (Mendoza Pérez y Belarra, 2015).

Durante su permanencia en el centro residencial Urrun, los jóvenes acuden a la escuela a actividades deportivas en Bilbao o en pueblos de los alrededores, ya que se intenta no colapsar con estos menores los mismos contextos educativos. De este modo, se dispersa a los jóvenes por las distintas escuelas públicas de Bizkaia (País Vasco), y ello provoca que algunos chavales tengan que hacer una verdadera travesía para llegar a su centro educativo. Con el centro de menores en la periferia, donde el trasporte urbano no es tan frecuente, la realidad de muchos consiste en madrugar en exceso de mañana, y encontrarse agotados al llegar la tarde (Mendoza Pérez y Belarra, 2015).

La semana desemboca en viernes, sábados y domingos considerados de tiempo libre para el menor: pueden salir -por cualquier sitio que no sea el pueblo- los viernes y domingos hasta las 20:30 como máximo y los sábados hasta las 22:30. Los horarios, sin embargo, vendrán definidos también por los servicios de autobuses que conectan Bilbao con el pueblo donde se encuentra Urrun.

Por tanto, a estos menores migrantes se les priva de la oportunidad de pertenecer a un vecindario y tejido social, ya que tienen un acceso muy limitado al ocio de tarde y nocturno en edades entre 15-18 años.

\section{Metodología utilizada}

Con la intención de saber cómo eran las realidades de los menores migrantes, realizamos una investigación en la que utilizamos una metodología etnográfica general, de abril del 2014 a junio del 2015, y, en particular, un taller participativo construido a partir de distintas técnicas artísticas y que aquí se centrará en su trabajo sobre la cartografía realizada (para más información véase Mendoza Pérez, 2017a; Mendoza Pérez y Morgade Salgado, 2016; 2018).

El taller se desarrolló entre el 26 de marzo y el 4 de junio de 2015, principalmente en un espacio cedido por el Museo de Bellas Artes de Bilbao, con la participación de cinco menores migrantes, más dos estudiantes de integración 
social y la primera autora de este artículo. En este espacio, realizamos un total de doce sesiones, una sesión semanal de dos horas. Por las calles de Bilbao y el centro de menores realizamos cinco sesiones más, una de ellas dedicada exclusivamente a la realización de la cartografía por Bilbao y que explicaremos más adelante.

\section{La cartografía}

Hoy en día tenemos al alcance miles de mapas, la mayoría de los que consultamos se han hecho de forma interesada, hegemónica y tradicionalmente han sido herramientas de poder (Acosta et al., 2017). Generalmente, esos mapas nos hablan del espacio físico, en sentido geográfico, por donde poder movernos o no; sin embargo, no dan cabida a las gentes que los transitan y a otro tipo de narrativas que nos hablen de prácticas, afectos, deseos o espacios simbólicos (Acosta et al., 2017).

Es por ello que hacer una cartografía se nos antojaba una estrategia adecuada para generar nuevas narrativas, aunando multitud de acontecimientos, acciones, descripciones, deseos e incluso reflexiones interconectadas. Además, la cartografía como práctica se despliega como acción para la reflexión (Acosta et al., 2017).

\section{El paseo por Bilbao}

El 3 de abril del 2015 cinco menores migrantes, una integradora social en prácticas y la primera firmante del artículo paseamos por Bilbao. El itinerario de este paseo fue diseñado previamente por los menores migrantes, con la intención de recorrer espacios que visitaban con asiduidad. Un paseo iniciado frente al cuartel de la Ertzaintza ${ }^{2}$ en Sarriko, barrio de Bilbao, y terminado en el centro cultural de la Alhóndiga, ahora denominado Azkuna Zentroa. Tanto el inicio como el final del paseo no fueron casuales, ya que ambos puntos están en conexión con el autobús que une Bilbao con Urrun.

2. La Ertzaintza es la policía autonómica del País Vasco. 
El paseo fue una invitación a salir a la calle a mirar, a escuchar, a poner el cuerpo y a hablar con estos jóvenes de sus experiencias en las calles de Bilbao; también una oportunidad a imaginar otros paisajes y recoger Tánger o Casablanca a través de sus narraciones y las fotos que guardaban con nostalgia en sus dispositivos móviles y compartieron con nosotras (Mendoza Pérez, 2017a; 2017b).

El mapa soñado

El producto final de la cartografía fue un mapa imposible donde Bilbao y alrededores (País Vasco, España) hacen frontera con Tánger (Marruecos). Este mapa imaginario, compuesto por un mapa de 2 x 1,4 metros de Bilbao y 65 x $50 \mathrm{~cm}$ de Tánger, habla de las prácticas en la ciudad de los cinco participantes, también de anhelos que hicieron en su lugar de origen.

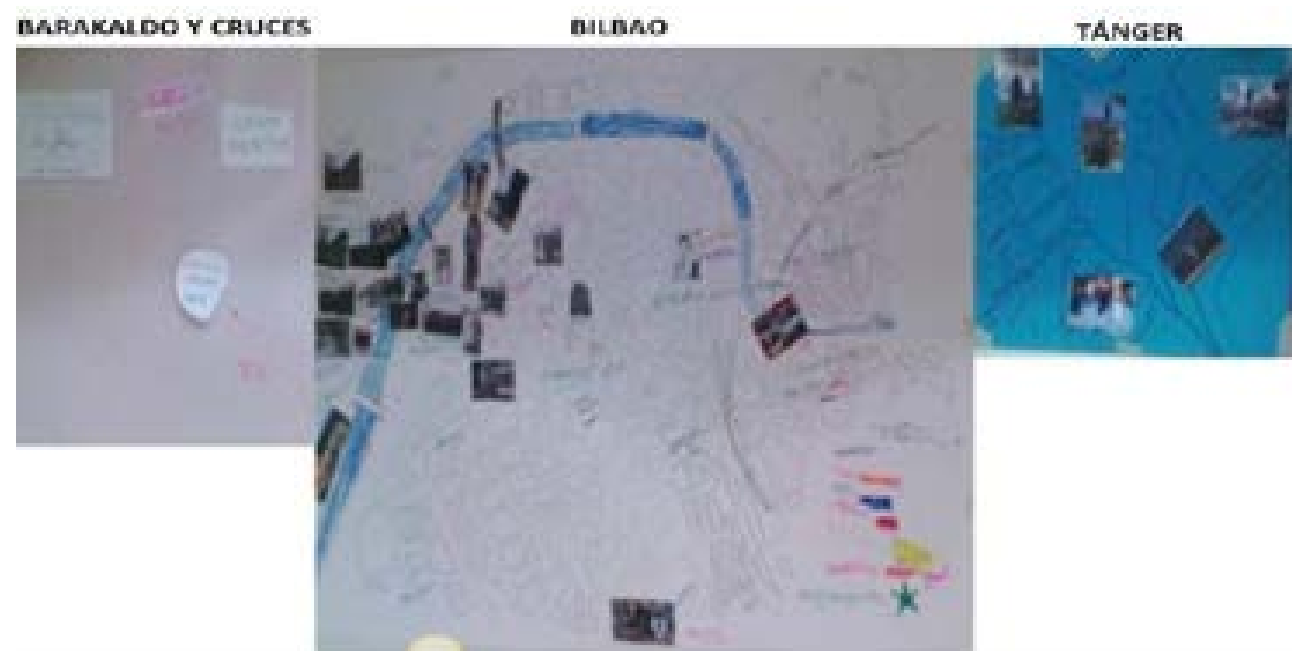

Imagen 1: Mapa conjunto de Bilbao y alrededores producto final de la cartografía.

Nota: Imagen 1 extraída de la cartografía.

\section{Wifi, centros comerciales y peluquerías}

A estos jóvenes se les limita la oportunidad de pertenecer al barrio y pueblo donde se sitúa Urrun; no obstante, buscan las formas de subvertir dichas normas. Gracias a los medios digitales la distancia física, las fronteras, no 
representan necesariamente siempre un obstáculo para generar intercambios (Mendoza Pérez y Morgade Salgado, 2018). Así, hay menores que encuentran formas de alterar el toque de queda del centro de menores, llegando incluso a entablar amistades con menores del pueblo:

Fragmento 1: Notas del diario de campo, 26 de mayo del 2015.

Llego al centro y veo que Mouad está en la «zona wifi», chateando y escuchando música. Dejo mis cosas en el despacho y bajo a ver qué hace. Está chateando con Mikel, su amigo del pueblo. Me habla un poco de su amigo, de cómo se conocieron y lo que les pasó el fin de semana pasado. Me enseña la foto de perfil del WhatsApp de Mikel para que lo conozca. Luego me pregunta qué puede hacer para recuperar algunas fotos que tiene subidas a Instagram, pero que ya no tiene guardadas en ese móvil. Le propongo, aunque pierda calidad, que haga una captura de la pantalla de cada imagen. Le convence la idea y lo va haciendo mientras intercambia mensajes con Mikel. Mikel también le manda aquellas fotos que tienen juntos y canciones que a ambos les gustan para que las vuelva a tener en el móvil y las pueda recuperar cuando no tenga conexión. Mouad, de vez en cuando, me pregunta cómo se escriben algunas palabras que quiere utilizar en los mensajes que le manda a Mikel.

Los móviles tejen puentes entre el aquí y el allí, siendo el allí múltiple, generando interconexiones con los paisanos que ya salieron del centro y/o están en Marruecos u otras partes de Europa, con la familia (Ruiz, 2009). Hoy en día es difícil estar aislado del resto del pueblo, ciudad, e incluso del mundo, nuestro globalizado mundo, aunque no haya desplazamiento geográfico.

Aun no participando en el núcleo de proyectos, planes, esquemas y directrices orientados a la revitalización urbanística y «milagro bilbaíno» (Vivas y Lekerikabeaskoa, 2014), los jóvenes protagonizan la ciudad, dejan su impronta en ella, haciendo un uso conformista, inconformista, o inesperado, de los lugares tal como nos son propuestos (VvaA, 2016). De este modo nos encontramos con tres espacios —zonas wifi, centros comerciales/culturales y peluquerías - en la ciudad de Bilbao en los que estos jóvenes se hacen especialmente visibles, participan y producen creativamente una cultura de iguales (Corsaro, 1990). 
Las zonas wifi

Buscar señal y/o «coger wifi» para comunicarse y estar conectados, más aún, interconectados, es lo que nos hace actuales (Komito, 2011; Komito y Bates, 2011). Nuestros ciudadanos protagonistas se mueven en la ciudad, como ellos dicen, para «coger wifi» o para conectarse a internet en los ordenadores de distintos centros culturales. En estos espacios con wifi, se encuentran con otros amigos, paisanos, etc., que buscan lo mismo:

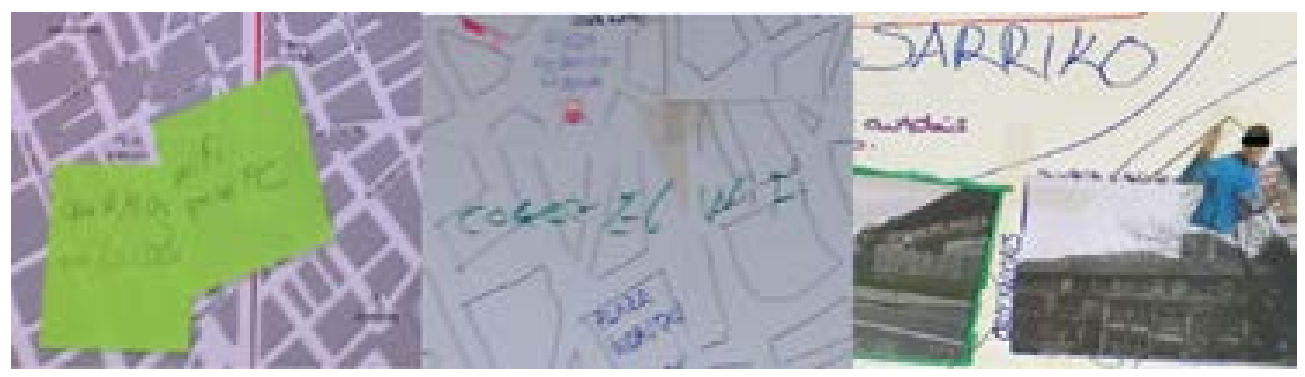

Imagen 2: «“Coger wifi" en Bilbao»

Nota: Comenzando por la izquierda, nos encontramos con el mapa de trabajo de Yassine, donde encima de donde sitúa la Alhóndiga, ahora denominada Azkuna Zentroa, ha colocado un post-it donde se puede leer: «wifi y para PC». En la imagen central, donde se presenta un extracto de la cartografía que hicieron, podemos ver como Omar ha marcado "coger el wifi" entre las plazas de Moyua y de Indautxu, ya que en esas zonas se puede acceder gratuitamente al Wifi-Bilbao. En la última imagen, también de la cartografía, vemos como Mouad, en Deusto, ha marcado que va al GazteGune por los ordenadores y a reunirse con los amigos.

Adolescentes migrantes, al igual que los autóctonos, que se hacen visibles en ciertos espacios como las plazas, los centros culturales, bibliotecas y centros comerciales para «coger wifi» (Pérez, Salcedo y Cáceres, 2012). «Coger el wifi» no es cosa sólo de adolescentes. Es una práctica que también aparece en los adultos; la ciudad digital debe disponer en su oferta de establecimientos que nos facilitan la contraseña si somos clientes. Es entonces cuando el poder adquisitivo limita el acceso a las «zonas wifi». Los adolescentes «in-migrantes» deben costearse con su paga semanal de $10 €$ sin sanciones su tarifa 
móvil, ${ }^{3}$ y con ello se quedan en las puertas de tiendas, cafeterías o plazas para «coger wifi». En tanto, adultos o jóvenes con poder adquisitivo, pueden entrar como consumidores a distintos establecimientos y disfrutar del wifi.

Así, las «zonas wifi» permiten estar conectados, son puntos de encuentro y socialización para adolescentes y jóvenes (migrantes), conversan, ligan, intercambian música, sacan fotos, etc. Estos espacios y calles por las que «cogen wifi» además de ser marcados en la cartografía que realizaron de Bilbao, son reconocibles en sus imágenes de perfil. Y también se destacan otros espacios menos visibles de los espacios públicos; los baños de la Alhóndiga de Bilbao son el escenario elegido por más de un menor para realizarse selfies, ya sea solo o acompañado, que más tarde compartirán en sus redes.

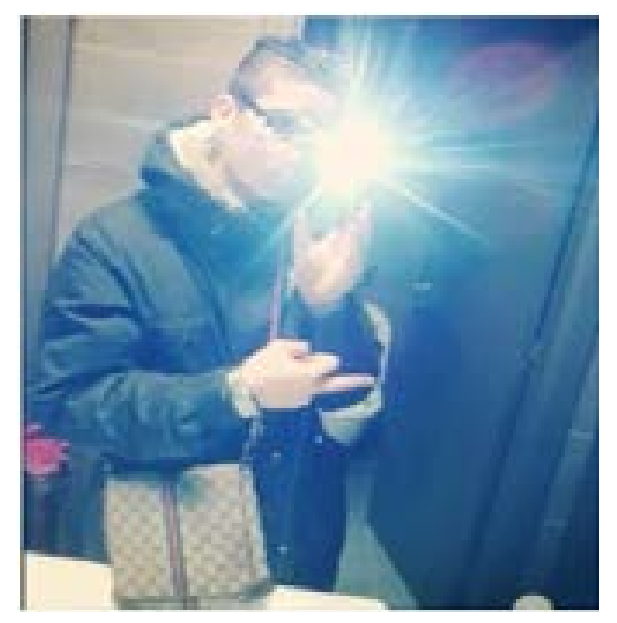

\section{Imagen 3: Reflejos en la Alhóndiga}

Nota: Foto de perfil de WhatsApp de Yassine cedida para este artículo.

Su imagen en redes y en la ciudad también escapará a la normatividad del centro que pretende limitar prácticas expresivas propias. Estos menores son

3. La mayoría de estos menores, cuando están en el centro de menores y tienen pocos recursos económicos, optan por la compañía Lycamobile, que tiene tarifas baratas para llamar al extranjero y bonos de datos asequibles. Además, es gratis llamar entre números de la misma compañía. Cuando la situación de estos menores mejora, suelen optar por compañías como Orange o Vodafone. Así mismo, hay muchos menores que mantienen dos números, uno de Lycamobile y otro de otra compañía, que usan diferenciadamente dependiendo de a quién llamen. 
también fácilmente reconocibles en la ciudad, pero no por las ropas grises que la institución pretende imponerles, lo son por sus peculiares gustos estéticos: singulares cortes de pelo, vestimentas deportivas y casuales (véase Mendoza Pérez y Morgade Salgado, 2018). La exuberancia de las estéticas que promueven los menores escandaliza a técnicos (Jones, 2013, p. 17) y choca con la estructura simbólica de victimización y la exclusión del consumo que ha conformado la Administración para estos menores (Gimeno, 2014, p. 153).

Pero la posesión y la adquisición de ropa, más allá de cubrir la necesidad básica de vestido, es un modo activo de relación, con objetos (Latour, 2015), sus iguales en edades, la ciudad y el mundo (Baudrillard, 2007, p. 223). Estos jóvenes son conscientes de que la ropa es un signo de posición social que actúa como parte de la identidad de clase (Bourdieu, 1984). Conciben la ropa como lenguaje con raíces corpóreas, puesto que los cuerpos vestidos los proyectan, preceden e introducen en la comunicación con los demás (Barthes, 1990; Lurie, 1991). De este modo, las ropas se presentan como un código y medio por el cual enviar mensajes sobre uno mismo (Barthes, 1990). Nuestros coinvestigadores no quieren verse con ropas compradas al por mayor que los identifique como «chicos de centros de menores», resaltando aún más sus diferencias de clase respecto a otros chicos y chicas españoles, entorpeciendo la creación y desarrollo de sus relaciones sociales, o mostrando un fracaso migratorio (Rodríguez, 2015, p. 334). Cuerpos y prácticas en la ciudad construyen identidades que conectan sus realidades transnacionales.

\section{Los centros comerciales y las peluquerías}

Decimos que el cuidado de la imagen corporal se contempla en varias prácticas sobre el cuerpo de uno mismo en el espacio público de las calles, pero también incluyen prácticas como el compartir fotos, ir de compras o cortarse el pelo en áreas comerciales. Para ir de compras suelen preferir grandes superficies como los centros comerciales, espacios que como para muchos adolescentes, tanto si se va a comprar o no, se han convertido en puntos de encuentro (Poveda, Morgade Salgado y González Patiño, 2012), donde poder performar sus looks (Goffman, 1981). Los looks, en su puesta en escena, son 
creaciones de una versión única e individual del yo a través de la adquisición de distintos bienes de consumo (Twigg, 2009), que transmiten información a sus iguales que no sería fácilmente traducible a palabras (Weber y Mitchell, 2004).

Fragmento 2: Notas del diario de campo del taller, 3 de abril del 2015.

Como acordamos en la sesión anterior del taller, quedamos todos juntos para tomar fotos que después utilizaremos para realizar la cartografía. Paseamos y sacamos fotos por los distintos espacios que los participantes nos han dicho que frecuentan. Llegamos por Deusto, a la altura de la ría, y sacamos fotos desde la orilla de enfrente al centro comercial Zubiarte. ${ }^{4}$ Después, cruzamos el puente y entramos al Zubiarte por el acceso de la terraza, espacio frecuentado mayoritariamente por adolescentes. Mientras subimos las escaleras a Mouad parece que le da un poco de vergüenza ir con nosotras (Sandra, la estudiante de prácticas, y yo). Jamal saca fotos de la Terraza y del supermercado. Mouad me da una vuelta por el centro enseñándome las tiendas y los sitios que le gustan. A diferencia de los cines y los restaurantes de comida rápida, todas las tiendas están cerradas porque es Viernes Santo, por lo que sólo miramos los escaparates.

En esta vuelta nos encontramos con muchos chavales del centro de menores, acompañados de compañeros y compañeras de clase o del centro escolar al que acuden. Tanto los jóvenes del centro, como el resto de amigos y conocidos que nos encontramos van vestidos impecables y de acuerdo a la moda imperante. Las chicas llevan largas melenas planchadas, pantalones de talle alto y zapatillas deportivas o bien de marca (Nike Air, Adidas) o con estampados coloridos. La mayoría de chicos, ya sean árabes o no, llevan el pelo rapado por los lados y lo de arriba más largo, a modo de tupé. Al igual que las chicas, los pantalones son pitillos y las zapatillas también son de marca o vistosas. El look de chándal también parece estar de moda. Algunos llevan gorras o gorros de lana. A diferencia de los chicos autóctonos, los chicos árabes con los que nos cruzamos, a modo de abrigo, suelen llevar cazadoras de materiales similares al cuero.

Las narraciones que acompañaron a la fotografía del Zubiarte, centro comercial en el corazón de Bilbao, hablan de prácticas de adquisición de ropa que parecen tener una menor relevancia y ser algo puntual comparado con

4. Centro comercial situado en el núcleo urbano de Bilbao y de muy fácil acceso. A escasos metros del Parque de Doña Casilda y del Museo de Bellas Artes de Bilbao. 
otras actividades como pasear, quedar con amigos, hablar con las chicas o estar en la terraza. Bien es cierto que el consumo en ocasiones de refrescos, chucherías, etc. se da como justificación de estar en este espacio en tanto que son consumidores.

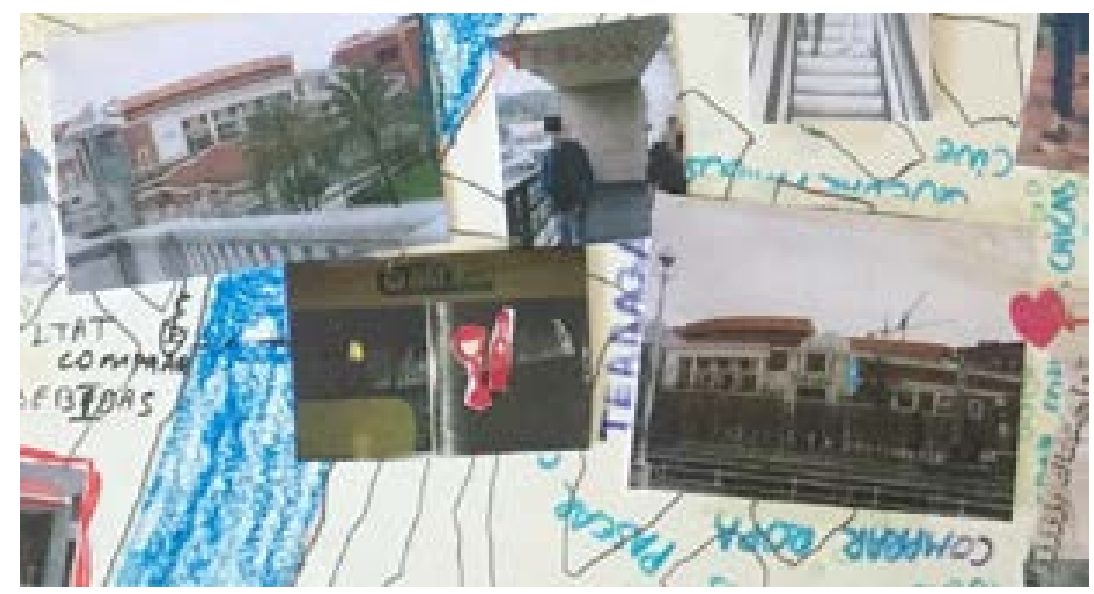

Imagen 4: Zubiarte: terraza, chicas, pasear, ropa.

Nota: Imagen 4 extraída de la cartografía.

No obstante, cuando su objetivo es exclusivamente adquirir ropa, con su dinero o el dinero que el centro les da anualmente para ropa, prefieren desplazarse a centros comerciales más alejados del núcleo urbano de Bilbao como el MaxCenter (Barakaldo, Bizkaia), porque hay más establecimientos comerciales, como por ejemplo la tienda Foot Locker donde les gusta comprarse las zapatillas.

Consumir es la vía para la integración en la estructura simbólica globalizada que se ha instituido para los jóvenes autóctonos, pertenecientes a una clase social media y de la que estos jóvenes parecen estar excluidos hasta que no trabajen (Gimeno, 2015; Vacchiano, 2015). Sin embargo, a pesar de dicha exclusión los menores migrantes generan alternativas divergentes, en ocasiones al margen de la ley (Mucchielli, 2013), que les permiten ampliar real o supuestamente su fondo de armario. Por un lado, es habitual ver que estos menores comparten en las redes sociales fotos con distintas estéticas, que han sido tomadas en los probadores de las tiendas, sin finalmente adquirir el producto. Pero también hay una fuerte red de solidaridad entre ellos, y el préstamo y/o intercambio de ropa es algo común. De este modo, unas zapa- 
tillas o una camiseta pueden ser usadas por más menores que el propietario. Por último, menores migrantes adquieren ropa y zapatillas de marca, que en la mayoría de ocasiones no son contabilizadas por el centro, pero que nos indican un poder adquisitivo generado más allá de la paga semanal de $10 €$ (Mendoza Pérez y Morgade Salgado, 2018).

Cortarse el pelo, como otra práctica comercial y de cuidado de uno mismo, les lleva a estos chicos a frecuentar peluquerías árabes en el Barrio de San Francisco o Bazarrate. En la cartografía hubo quien marcó su peluquería de confianza como uno de los lugares de la ciudad a los que acudía con frecuencia (véase imagen 5).

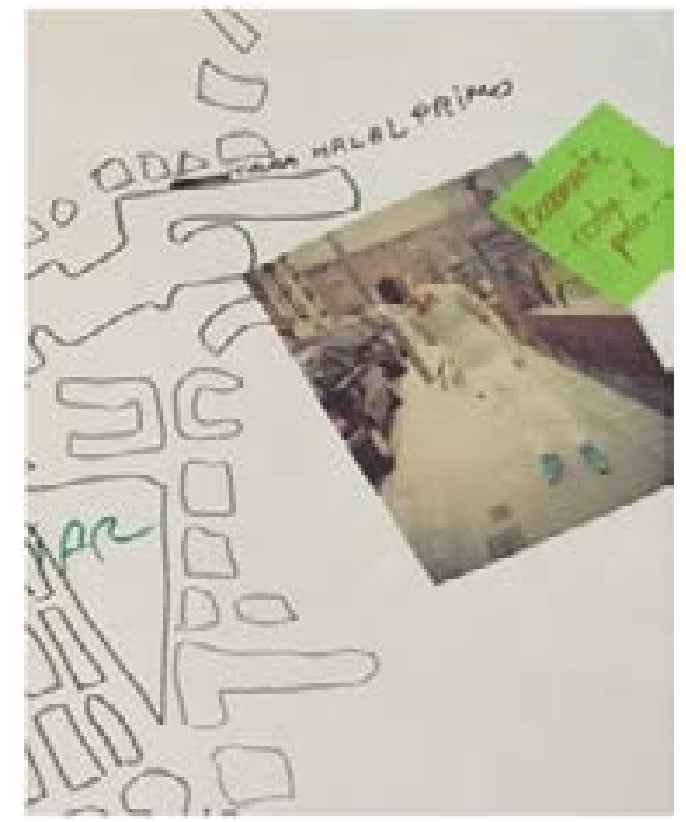

Imagen 5: Bazarrate corta el pelo.

Nota: Imagen 5 extraída de la cartografía.

Las peluquerías son espacios en los que arreglarse el cabello, y son el lugar idóneo para la interacción y el intercambio con otras personas de su país (Alexander, 2003; Byrd y Tharps, 2001; Edwards, 2008). Para nuestros jóvenes migrantes las peluquerías, tanto en Marruecos como en Bilbao, son un espacio en el que pueden, además de cortarse el pelo, tener una charla agradable sobre las cosas que les importan. Y es que el ir a la peluquería es una ocasión más para el desarrollo, mantenimiento y difusión de la cultura más allá de la estética que también compartirán en las redes sociales: 
Fragmento 3: Notas del diario de campo, 13 de abril del 2017.

Quedo con Rayan para dar un paseo por Bilbao. Le cuento cómo nos fue en la presentación de nuestro trabajo sobre estéticas y masculinidades en el congreso «Arab Masculinities Anthropological Reconceptions». A partir de ahí seguimos hablando sobre las peluquerías. Me cuenta que ha venido un peluquero nuevo, de Tánger, a la peluquería donde él se corta el pelo. Casualmente, el peluquero nuevo conocía a su familia de vista y a él le había visto alguna vez cuando era pequeño.

La creación de peinados que transmitan quiénes son o quieren ser no acontece en un plano individual, sino que son una coconstrucción que surge de la interacción en distintos contextos como las redes sociales, el grupo de amigos, el colegio, la peluquería u otros espacios. $\mathrm{Y}$ «coger wifi» y acceder a las redes sociales les permite a estos jóvenes buscar inspiración, compartir sus nuevos cortes de pelo y obtener feedback de sus contactos (Chittenden, 2010) dando a conocer a los jóvenes autóctonos peluquerías marroquíes especialmente dadas a los cortes de pelo más actuales. Así, los cortes de pelo que lucen estos chicos evidencian su posición simultáneamente de jóvenes y migrantes dando lugar a formas complejas de culturas e identidades híbridas que mezclan el aquí y el allí a la par que están conectados a la cultura juvenil global (Mendoza Pérez y Morgade Salgado, 2018).

Nos encontramos a jóvenes que desde una posición periférica y marginal participan en los procesos de globalización convirtiéndose no sólo en receptores, sino también en promotores y productores de las culturas juveniles globales (Corsaro, 1992). De forma práctica la globalización se presenta y representa como un continuo en la vida de estos jóvenes donde se dan interacciones locales, nacionales y globales.

\section{A modo de cierre}

Salir a la calle a mirar, a escuchar, a poner el cuerpo y a hablar con los denominados como «los otros» sobre sus propias experiencias en la ciudad abre la puerta a una realidad no tan invisible, aislada o marginal. Las prácticas y los saberes que estos jóvenes migrantes nos han prestado han desvelado otras formas de hacer Bilbao. Un Bilbao donde los adolescentes migrantes son 
conscientes de que en lo urbano se ejercen relaciones de poder, dominación y también resistencia, construyendo ciudadanía (entre otras cosas: capacidad de acceso, presencia y actividad en la ciudad) en un contexto propenso a producir exclusión (negación de aquel acceso, presencia y actividad; Moncusí Ferré, 2018). Las prácticas que realizan estos jóvenes migrantes nacen de los márgenes y son cruciales para reconstituir su identidad en un país, ciudad y espacio extraño, y a través de las redes también en el de origen (Mendoza Pérez y Morgade Salgado, 2018). Así, «coger wifi», vestirse y peinarse cobra una dimensión distinta, y también lo hacen las prácticas adyacentes como comprar ropa, que forman parte de ese ensamblaje necesario para reivindicarse como ciudadano e igual, para expresarse con los limitados recursos que estos jóvenes tienen a su alcance.

Por otra parte, la posibilidad de moverse físicamente por la ciudad, aunque se limite físicamente, contempla la posibilidad de ser móvil de forma virtual o imaginada para conectarse también con otras personas, conocimientos, países e instituciones (Mendoza Pérez, 2017b). Los medios digitales se muestran, en especial, en aquellas personas como los menores migrantes con movilidad restringida, medios para fugarse y ser móviles sin necesidad de que haya un desplazamiento físico. Es decir, usan las tecnologías digitales como instrumento para su liberación. Con ello la migración no sería un estado final, de llegada a un punto de destino; los migrantes, gracias a los medios digitales, estarían en un estado continuo de movilidad virtual-encarnada, real-imaginada y local-transnacional (Veale y Donà, 2014).

La socialización de los jóvenes migrantes no debe entenderse como una progresión en la que cada vez van interactuando en más campos sociales de acción que ellos no construyen, sino que hay que comenzar a entender cuán interrelacionados están los diversos campos sociales en los que estos menores migrantes participan, unos campos que crean, o que reconfiguran, o a los que llegan (Corsaro, 1992). La comprensión de la interrelación de estos campos es una cuestión fundamental para complejizar la comprensión de estos jóvenes como sujetos migrantes, y la ciudad parece ser el escenario idóneo para comenzar a entender a los adolescentes migrantes y sus mundos. Estos adolescentes y jóvenes migrantes, más allá de ocupar físicamente una serie de espacios, se revindican como ciudadanos plenos y en constante interacción y 
negociación entre amigos, paisanos, familia, la escuela, la comunidad en el país de origen, etc. (Christensen y O’Brien, 2003).

\section{Referencias}

Acosta, Gil-Founier; Jaenick; Jorgina, Zappala, Esquillos, González, Cadena, Los Madriles, SEGIB, CCEMX y ZAC. (2017). Cómo hacer un mapeo colectivo. La aventura de aprender. Recuperado de http:// laaventuradeaprender.educalab.es/documents/10184/51639/C\%C3\%B3 mo+hacer+un+mapeo+colectivo/

Aierbe, P., Taulats, A., Manzani, L., Y Luciani, S. (2010). Menores en riesgo. Prácticas excepcionales de las administraciones. San Sebastian: sos Racismo.

Alexander, B. K. (2003). «Fading, Twisting, and Weaving: An Interpretive Ethnography of the Black Barbershop as Cultural Space». Qualitative Inquiry 9, 105-28.

Ararteko (2014). Informe anual al Parlamento Vasco. Informe de la Oficina de la Infancia y la Adolescencia. Vitoria-Gasteiz: Ararteko.

- (2016). Informe anual al Parlamento Vasco. Informe de la Oficina de la Infancia y la Adolescencia. Vitoria-Gasteiz: Ararteko.

Arrazola, N. (2014). «Lo que no tendría que volver a pasar. El dispositivo nocturno de primera acogida para menores no acompañados en Cataluña». En Empez, N. (coords.). Dejadnos crecer. Menores migrantes bajo tutela institucional. Barcelona: Virus Editorial.

BARTHEs, R. (1990). The Fashion System. Berkeley: University of California Press.

Baudrillard, J. (2007). El sistema de los objetos. México: Siglo XXI.

Bauman, Z. (2005). Vidas desperdiciadas. Barcelona: Paidós. 
Bourdieu, P. (1984). Distinction: A Social Critique of the Judgement of Taste. Harvard University Press.

Byrd, A. Y Tharps, L. (2014). Hair Story: Untangling the Roots of Black Hair in America. New York: Macmillan.

Chittenden, T. (2010). «Digital Dressing Up: Modelling Female Teen Identity in the Discursive Spaces of the Fashion Blogosphere». Journal of Youth Studies 13, 505-20. DOI: https://doi.org/10.1080/13676260903520902

Corsaro, W. A. (1992). «Interpretive Reproduction in Children〉s Peer Cultures». Social Psychology Quarterly, 160-177.

Delgado, M. (2007). Sociedades movedizas: pasos hacia una antropología de las calles. EURE, 33(98), 142-144.

EMPEz, N. (2015). “iSolo valiente!» Los menores que migran solos de Marruecos a Cataluña. Tesis Doctoral, Universidad Autónoma de Barcelona. Disponible en: http://tdcat.cesca.es/bitstream/ handle/10803/287989/nev1de1.pdf? sequence $=1$

García Almirall, P. (2008). «Inmigración y vivienda: el proceso de integración desde el análisis y la prospectiva de la formación de hogares y su acceso a la vivienda. Una aproximación a las 7 áreas metropolitanas españolas». Arquitectura, ciudad y entorno III (8), 249-283.

Gimeno, C. (2014). Buscavidas: la globalización de las migraciones juveniles. Zaragoza: Prensas de la Universidad de Zaragoza.

- (2015). «Recherche sur les migrations clandestines des jeunes et e'thique du travailleur social chercheur». Le sociographe 5, 51-70.

Goffman, E. (1959). The Presentation of Self in Everyday Life. Nueva York: Doubleday Anchor Books. Citamos de la edición española (1981): La presentación de la persona en la vida cotidiana. Buenos Aires: Amorrortu.

Jones, O. (2013). Chav's. La demonización de la clase obrera. Madrid: Capitan Swing. 
Koмiтo, L. (2011). Social Media and Migration: Virtual Community 2.0. Journal of the American Society for Information Science and Technology, 62(6), 1075-1086. DOI: 10.1002/asi.21517

Koмito, L., Y BATES, J. (2011). «Migrants' Information Practices and Use of Social Media in Ireland: Networks and Community». In Proceedings of the 2011 iConference, 289-295. DoI: http://dx.doi. org/10.1145/1940761.1940801

Latour, B. (2015). «¿El cosmos de quién?, ¿qué cosmopolítica? Comentarios sobre los términos de paz de Ulrich Beck». Pleyades, 14, 43-39.

LurIE, A. (1992). The Language of Clothes. London, UK: Bloomsbury.

Mendoza Pérez, K. (2017a). Adolescentes y jóvenes migrantes en Bizkaia: prácticas de vida y socialidad. Tesis Doctoral: Universidad Autónoma de Madrid.

- (2017b). «Tecnologías digitales, cuerpo y estructura familiar». Athenea digital: revista de pensamiento e investigación social, 17(3), 0297-309. Recuperado de https://doi.org/10.5565/rev/athenea.2225

- Belarra, I. (2015). «Menores migrantes en Bizkaia: Entre la protección y el control». Revista Internacional de Estudios Migratorios, 5(2), 227259.

- Morgade Salgado, M. (2016). «Same Plans, Different Strategies: The Multiple Faces of Resistance». Pedagogy, Culture \& Society, 24, 617-30. DOI:10.1080/14681366.2016.1197962

- Morgade Salgado, M. (2018). Doing Masculinity: The 'look' of unaccompanied male migrant teenagers from the Maghreb. Men and Masculinities. DOI: https://doi.org/10.1177/1097184X17748169

Moncusí Ferré, A. (2017). «Espacios públicos, condición inmigrante, orden institucional y derecho a la ciudad. Reflexiones a propósito de Valencia». kult-ur, 4(8), 73-92. DoI: https://doi.org/10.6035/Kultur.2017.4.8.2 
Morgade Salgado, M., Poveda, D., y González Patiño, J. (2014). «Del hogar a la ciudad como camino de ida y vuelta en el desarrollo de la identidad: el caso de las rutinas de la infancia urbana de clase media/alta en Madrid». Educação e Sociedade.

Mucchieldi, L. (2013). «Violence: de quoi parle-t-on?» Sciences Humaines [On Line] 247.

Pérez, M., Salcedo, R., y Cáceres, G. (2012). «Apropiación y control social en un centro comercial de Santiago: prácticas socioespaciales y significaciones adolescentes». EURE (Santiago), 38(113), 53-75. Recuperado de http://dx.doi.org/10.4067/S0250-71612012000100003

Poveda, D., Morgade Salgado, M., Y González Patiño, J. (2012). «Children at home in Madrid». ETNIA-E: Cuadernos de Investigación Etnográfica sobre Infancia, Adolescencia y Educación del IMA/FMEE.

Rodríguez, A. (2015). Chicos marroquíes buscando su futuro: la experiencia de migrar, entre la violencia estructural y las violencias cotidianas. Tesis Doctoral. Universidad de Granada, Granada, España.

RuIz, A. (2009). «La perspectiva transnacional de las migraciones: desafíos e implicaciones prácticas». Cuadernos Bakeaz, 93. Bilbao: Bakeaz.

TwigG, J. (2014). «Clothing, Identity and the Embodiment of Age». Textile-led Design for the Active Ageing Population, 13.

VacChiano, F. (2014). «Beyond Borders and Limits: Moroccan Migrating Adolescents between Desire, Vulnerability and Risk». Saúde e Sociedade, 23, 17-29.

VvaA (2016). El Paseo de Jane. Tejiendo redes a pie de calle. Madrid: Modernito Books.

Veale, A. Y Donà, G. (2014). «Complex Migrations, Migrant Child and Family Life Trajectories and Globalization». En Veale, Angela y Donà, Giorgia (ed.). Child and Youth Migration (pp. 1-20). New York: Palgrave Macmillan. DoI: 10.1057/9781137280671 
Vivas, I. Y Lekerikabeaskoa, A. (2014). «Bilbao Blade Runner: desde las sombras del titanio... Tácticas estéticas e iconográficas de construcción del paisaje urbano en la remodelación del centro cultural de la Alhóndiga». Ankulegi: gizarte antropologia aldizkaria= revista de antropología social, 18, 43-63.

Weber, S. y Mitchell, C. (2004). Not Just Any Dress: Narratives of Memory, Body, and Identity, Vol. 220. New York: Peter Lang. 